\title{
The Impact of Provider Continuity Care on Quality of Care of Patients With Type 2 Diabetes Mellitus in the Family Medicine Clinic Of UCTH, Calabar, Nigeria
}

Udonwa NE* and Okoi NO

Department of Family Medicine, University of Calabar Teaching Hospital, Calabar, Nigeria

\begin{abstract}
Background: Diabetes mellitus in sub-Saharan Africa is a chronic and debilitating disease with increasing morbidity and mortality. The increased morbidity and mortality could be attributed to poor approach to management. One of these poor approaches could be lack of continuity of care.

Aim: To investigate the impact of provider continuity care on quality of care for adult patients with type 2 diabetes mellitus by comparing the quality of care of the adult patients managed on provider continuity basis and those managed by random care providers.

Method: One hundred and twenty six adult patients with type 2 diabetes mellitus were recruited into the facilitybased on cross sectional descriptive study that lasted for four months. Sixty-three adult patients received provider continuity care and sixty-three adults received random care. The quality of care measures used in this study included fasting plasma glucose (FPG), glycosylated hemoglobin (HbAic) and blood pressure (BP) control. The data collected was analyzed using statistical package for social sciences (SPSS) software version 15

Results: Among the study patients, there were more females $72(57.2 \%)$ than males $54(42.8 \%)$. The commonly presented symptoms of polyuria and polydypsia were seen in $76.2 \%$ and $35.7 \%$ of the patients respectively. There was a significant difference in the glycaemic control using the fasting plasma glucose level between patients with provider continuity care and random care $(5.62 \pm 2.04 \mathrm{vs}$. $8.53 \pm 3.18)(p<0.001)$ and in the quality of care between patients with provider continuity care and random care using HbAic standard respectively $(p<0.011)$. There was no significant difference in terms of blood pressure control between provider continuity care and random care $(p>0.365)$.

Conclusion: This study found an association between provider continuity care and quality of care in adult patients with type 2 diabetes mellitus. Consequently, provider continuity care is judged to be more beneficial in the management of type 2 diabetes mellitus in our environment.
\end{abstract}

Keywords: Continuity care; Quality of life; Type-2 Diabetes mellitus

\section{Background}

Continuity care holds an important position in the practice of medicine [1]. It is rooted in a long term patient-physician relationship, in which the physician knows the patients' history based on familiarity and close contact. The physician then integrates that history into new information and decision from a whole patient perspective.

Continuity care has been shown to have an important consequence in the organization and delivery of health care to patients with chronic diseases. It's benefits include preventive care through the use of improved compliance with medication [2], improved physician recognition of medical problems [3], reduced rate of hospital admission and emergency department, and improved patients' satisfaction with the care and follow-up of appointment [4]. In particular continuity care has been found to be beneficial in the management of patients with chronic disease conditions $[1,5]$ including a common and potentially disabling chronic disease like type 2 DM that accounts for most cases of diabetes mellitus worldwide [6]. Type 2 diabetes mellitus is a chronic debilitating disease with increasing prevalence in Nigeria and SubSaharan Africa. Lack of proper care has led to increase in morbidity and mortality among the adult type 2 diabetes mellitus.

In the past two decades, health care delivery has undergone changes that have undermined the ability of patients to choose and remain with their regular health care providers. Health planners, sometimes change physicians' plans through postings, which may require patients to change physicians periodically. Recently, changes in the organization of health care services, coupled with the, frequent rotation of physicians within the same health care facility, have posed threats to the maintenance of a continuous patients-providers relationship. Some studies have reported the negative impact that discontinuity of care could have in the management of chronic diseases such as type 2 diabetes mellitus $[7,8]$.

The objective of this study was to examine the effect of random care providers and the regular providers on plasma glucose and blood pressure control in a sample of adult patients with type 2 diabetes mellitus. Through the investigation of the effect of providers' continuity care on quality of care of the adult patients this study would determine the type of tool to use in the management of patients with chronic diseases like type 2 diabetes mellitus. Consequently, the information obtained from this study will be used to improve quality of care, reduce

*Corresponding author: Udonwa NE, Department of Family Medicine, University of Calabar Teaching Hospital, Calabar, Nigeria, E-mail: nudonwa@yahoo.com

Received May 23, 2013; Accepted June 17, 2013; Published June 21, 2013

Citation: Udonwa NE, Okoi NO (2013) The Impact of Provider Continuity Care on Quality of Care of Patients With Type 2 Diabetes Mellitus in the Family Medicine Clinic Of UCTH, Calabar, Nigeria. Contact Can Change a World. J Gen Pract 1 : 109. doi:10.4172/2329-9126.1000109

Copyright: (c) 2013 Udonwa NE, et al. This is an open-access article distributed under the terms of the Creative Commons Attribution License, which permits unrestricted use, distribution, and reproduction in any medium, provided the original author and source are credited. 
Citation: Udonwa NE, Okoi NO (2013) The Impact of Provider Continuity Care on Quality of Care of Patients With Type 2 Diabetes Mellitus in the Family Medicine Clinic Of UCTH, Calabar, Nigeria. Contact Can Change a World. J Gen Pract 1: 109. doi: 10.4172/2329-9126.1000109

Page 2 of 6

cost, morbidity and mortality through promotion of diabetic education and self management of the established disease.

\section{Subjects, Materials and Methods}

The cross sectional descriptive study was conducted in Family Medicine Department of University of Calabar Teaching Hospital, (UCTH), Calabar, the capital city of Cross River State, Nigeria. The department comprises the GOPC (General Out-Patient Clinic), Staff clinic, Consultancy services clinic and Special treatment clinic (Presidential Emergency Plan for Aids Relief and sexually transmitted infections). The UCTH is a Federal Tertiary Hospital and the largest public health facility in Cross River State. It is made up of various specialties, sub-specialties, a research institute and administrative unit. It offers primary, secondary and tertiary healthcare, to the people of Cross River State, the neighbouring States of Akwa Ibom, Benue, Abia, and neighboring countries of Cameroon and Equatorial Guinea. The GOPC serves as the gateway to the Hospital through the provision of primary medical care services.

Adult patients presenting with symptoms and signs suggestive of diabetes mellitus were studied using a sampling frame of only those diagnosed with type 2 diabetes mellitus. All type 2 diabetes mellitus patients with fasting plasma glucose of $7 \mathrm{mmol} / \mathrm{L}$ and above within the age range of 35 to 75 years who gave consent to participate in the study were recruited for the study. They were divided into the intervention and control groups through simple random sampling. The letters $A$ and $B$ were written on separate pieces of paper by the researcher in equal numbers such that all added together would equal the total sample size. These pieces of paper were then folded and pooled together in a paper bag and mixed thoroughly. The participants picked a piece of paper from the bag without replacement. The process was followed until the last piece of paper in the bag was picked. All the patients that picked letter A were in the intervention group and those that picked letter B were in the control group. The patients that were in the intervention group received provider continuity care and those in the control group received random care.

A twelve-item structured questionnaire that contained questions on demography, clinical diagnosis and treatment of type 2 diabetes mellitus was developed and used to screen patients that came to GOPC after a pretest to determine the patients' understanding, acceptance and clarity of the questionnaire items and to identify logistics problems.

Clinistix Test Strips (CTS) was used to screen the urine of patients that presented with symptoms and signs suggestive of diabetes mellitus while the precision glucometer (True Track Model NDC 561510850-50 USA) was used, to estimate the fasting plasma glucose of adult patients and in monitoring patients' fasting plasma glucose throughout the study period. The heights of all the recruited patients were measured with a stadiometer (Marsdens w9.01.2891066 London) while their systolic and diastolic blood pressures were measured with a mercury sphygmomanometer (Accuson, England) in sitting and standing positions. A simple bathroom weighing scale (Hana weighning scale, China) was used to measure weights of the patients in kilogram (kg). HbAic was evaluated using Glycosylated Hemoglobin Machine (Model: 1Gm-0023, USA).

Those who came to the clinic for the first time and their urine tested positive for glucose were given appointment (with the follow-up patients) to come the following day after overnight (at least for 8 hours) fast for fasting plasma glucose estimation. They were instructed not to take any medication except water and should report to the clinic in the morning. Those, whose fasting plasma glucose were $7 \mathrm{mmol} / \mathrm{L}$ and above were recruited into the study.

All the recruited patients were divided into two groups. The intervention group and the control group through simple balloting. Those in the intervention group received provider continuity care and those in the control group received Random Care. To ascertain that, the patients in the control group did not receive provider continuity care, their folders were kept and reshuffled to different doctors on each clinic visit by the researcher. Associated medical history such as hypertension, heart failure, renal failure, urinary tract infection, recurrent skin infection, chronic wound infection and weak penile erection, diabetic neuropathy were taken and entered into each patient's medical records.

At the end of each clinic visit, the researcher reviewed the medical records of all the patients to check for defaulters, type of oral hypoglycaemic drugs given, insulin and diabetes education. The researcher reached the defaulters through phone calls or home visit. Six diabetic patients from provider continuity care and five from Random Care were referred to Medical Out-Patients Department (MOPD) of Internal Medicine because of high and difficult to control blood pressure. The researcher followed-up the medical treatment given to these 11 diabetes patients referred to MOPD throughout the period of the study. The six diabetic patients from provider continuity were made to see the same doctor during their clinic visit days and the five from random care were made to see any doctor during their clinic visit days.

At the end of the study period, blood samples were collected from each patient for fasting plasma glucose and glycosylated haemoglobin (HbAic) estimation.

The data collected was analyzed using the statistical package for social sciences (SPSS) software version 15. A p-value of less than 0.05 was taken to be significant. The student $\mathrm{t}$-test and chi-square test (x2) were used for significant testing.

This study underwent ethical review and received approval from the Ethical Committee of University of Calabar Teaching Hospital (UCTH). Each patient signed or thumb printed the informed consent to participate in the study. During data collection and subsequent data analysis, all the relevant ethical issues that were required in interventional studies were respected. Patients recruited into the study were duly informed about the purpose and procedure of the study. Participation was voluntary and each individual was free to leave the study at any time without any penalty.

\section{Results}

One hundred and thirty-one adult patients with type 2 diabetes mellitus attended the diabetes clinic during the course of the study. Five patients dropped from the study and follow-up, three from the provider continuity care and two from the random care giving a total attrition of (3.8\%). There were $54(42.8 \%)$ male and 72 (57.2\%) females Table 1 giving a ratio of female to male diabetics as 1.3:1. There was no significant difference in the gender distribution among this study group, $(p>0.746)$.

Their ages ranged from 35 years to 75 years, with the mean age of 50.5 (SD2.50).

Petty traders made up $33.33 \%$ of the patients while there were civil servants $(29.4 \%)$, professionals $(21.4 \%)$, teachers $(8.7 \%)$, farmers (4.0\%) and housewives (3.2\%) also. 
Citation: Udonwa NE, Okoi NO (2013) The Impact of Provider Continuity Care on Quality of Care of Patients With Type 2 Diabetes Mellitus in the Family Medicine Clinic Of UCTH, Calabar, Nigeria. Contact Can Change a World. J Gen Pract 1: 109. doi: 10.4172/2329-9126.1000109

Page 3 of 6

Table 2 shows a multiple response of the common presenting symptoms among the adult patients with type 2 diabetes mellitus in the study center. Seventy-six percent complained of polyuria, $35.7 \%$ of polydypsia, $36.5 \%$ of weight loss, $20.6 \%$ of numbness, $15.9 \%$ of blurred vision, $3.2 \%$ of polyphagia, and $1.6 \%$ each of dizziness, recurrent skin infection and poor penile erection.

Table 3 shows the glycaemic control between the provider continuity care and random care providers groups. The glycaemic control with the provider continuity care showed $51.6 \%$ had good glycaemic control and $48.4 \%$ had poor glycaemic control while the random care provider showed $18.6 \%$ with good glycaemic control and $65.9 \%$ with poor glycaemic control. There was significant difference in the glycaemic control between provider continuity care and random care provider $(p<0.001)$. A total of $34.1 \%$ had good glycaemic control while $65.9 \%$ had poor glycaemic control.
Table 4 shows the quality of care between the provider continuity care and random care provider groups. The mean glycosylated hemoglobin for PCC was $6.56 \pm 2.28$ with $87.1 \%$ with good glycaemic control and $12.9 \%$ with poor glycaemic control while the mean glycosylated hemoglobin for RCP was $7.56 \pm 2.40$, with $47.5 \%$ having good glycaemic control and $52.5 \%$ having poor glycaemic control. A total of $65.1 \%$ havd good glycaemic control and $34.9 \%$ had poor glycaemic control. There was a significant difference in the quality of care between the adult diabetic patients with provider continuity care and patients with random care providers, $(p<0.011)$.

From Table 5 the hypertensive males were $19.0 \%$ while female hypertensives were $40.0 \%$ and $14 \%$ of the adult patients were underweight with males $7.9 \%$ and females $6.4 \%$. Twenty-nine percent were of normal weight with males $15.1 \%$ and females $13.5 \%$. Eleven percent was overweight with males $7.1 \%$ and females $4 \%$. Forty-six

\begin{tabular}{|c|c|c|c|c|c|}
\hline & \multicolumn{4}{|c|}{ Sex } & \multirow{3}{*}{ Total $\mathbf{N}(\%)$} \\
\hline & \multicolumn{2}{|c|}{ Male } & \multicolumn{2}{|c|}{ Female } & \\
\hline & ${ }^{*}$ PCC N (\%) & ${ }^{* *}$ RCP N (\%) & *PCC N (\%) & ${ }^{* *}$ RCP N (\%) & \\
\hline \multicolumn{6}{|l|}{ Age (In Yrs) } \\
\hline $35-44$ & $6(11.1)$ & $7(13.0)$ & $6(8.3)$ & $5(6.9)$ & $24(19.1)$ \\
\hline $45-54$ & $8(14.8)$ & $7(13.0)$ & $14(19.4)$ & $15(20.8)$ & 44 (34.9) \\
\hline $55-64$ & $7(13.0)$ & $8(14.8)$ & $13(18.1)$ & $12(16.7)$ & $40(34.9)$ \\
\hline $65-74$ & $6(11.1)$ & $5(9.3)$ & $3(4.2)$ & $4(5.6)$ & $18(14.3)$ \\
\hline 75 and above & $0(0)$ & $0(0)$ & $0(0)$ & $0(0)$ & $0(0)$ \\
\hline Total & $27(21.6)$ & $27(21.6)$ & $36(28.6)$ & $36(28.6)$ & $126(100)$ \\
\hline \multicolumn{6}{|l|}{ Occupation } \\
\hline Petty Trading & $2(1.6)$ & $3(2.4)$ & $18(14.3)$ & $19(15.1)$ & $45(33.3)$ \\
\hline Civil Service & $10(7.9)$ & $10(7.9)$ & $9(7.1)$ & $8(6.3)$ & $37(29.4)$ \\
\hline Business & $12(9.5)$ & $10(7.9)$ & $2(1.6)$ & $3(2.4)$ & $27(21.4)$ \\
\hline Teaching & $3(2.4)$ & $4(3.2)$ & $2(1.6)$ & $2(1.6)$ & $11(8.7)$ \\
\hline Farming & $0(0)$ & $0(0)$ & $3(2.4)$ & $2(1.6)$ & $5(4.0)$ \\
\hline Housewives & $0(0)$ & $0(0)$ & $2(1.6)$ & $2(1.6)$ & $4(3.2)$ \\
\hline Total & $27(21.4)$ & $27(21.4)$ & $36(28.6)$ & $36(28.6)$ & $126(100)$ \\
\hline
\end{tabular}

${ }^{*} \mathrm{PCC}$ : provider continuity care, ${ }^{* *} \mathrm{RCP}$ : Random care provider

Table 1: Age, Occupation and Sex of adult patients with type 2 diabetes mellitus $N=126$.

\begin{tabular}{|c|c|c|}
\hline Symptoms & Frequency (N) & Percentage (\%) \\
\hline Polyuria & 96 \\
\hline Weight-loss & 46 \\
\hline Polydypsia & 45 \\
\hline Numbness & 26 & 36.2 \\
\hline Blurred vision & 20 & 35.5 \\
\hline Polyphagia & 4 & 20.6 \\
\hline Dizziness & 2 & 3.7 \\
\hline Poor erection & 2 & 1.6 \\
\hline Recurrent wound infection & 2 & 1.6 \\
\hline
\end{tabular}

Table 2: Common presenting symptoms among patients with type 2 diabetes mellitus $N=126$.

\begin{tabular}{|c|c|c|}
\hline Type of Care & Good Control N (\%) & Poor Control N (\%) \\
\hline Providers continuity care & $34(51.6 \%)$ & $31(48.4 \%)$ \\
\hline Random care & $11(18.6 \%)$ & $50(81.4 \%)$ \\
\hline Total & $45(34.1 \%)$ & $81(65.9 \%)$ \\
\hline
\end{tabular}

Table 3: Glycaemic control among patients with type 2 diabetes mellitus with provider continuity care and random care $(N=126)$.

\begin{tabular}{|c|c|c|c|}
\hline Quality of Care & Mean HbAic & Good control N (\%) & Poor control N (\%) \\
\hline Provider continuity care (PCC) & $6.56 \pm 2.28$ & $57(87.1 \%)$ & $8(12.9 \%)$ \\
\hline $\begin{array}{c}\text { Random care } \\
\text { Provider (RCP) }\end{array}$ & $7.56 \pm 2.40$ & $29(47.5 \%)$ & $32(52.5 \%)$ \\
\hline Total & & $\mathbf{8 6}(\mathbf{6 5 . 1 \% )}$ & $\mathbf{4 0}(\mathbf{3 4 . 9 \% )}$ \\
\hline
\end{tabular}

Table 4: Comparison of quality of care between patients with Povider continuity care and Random care using $\mathrm{HbAic}(\mathrm{N}=126)$. 
Citation: Udonwa NE, Okoi NO (2013) The Impact of Provider Continuity Care on Quality of Care of Patients With Type 2 Diabetes Mellitus in the Family Medicine Clinic Of UCTH, Calabar, Nigeria. Contact Can Change a World. J Gen Pract 1: 109. doi: 10.4172/2329-9126.1000109

Page 4 of 6

\begin{tabular}{|c|c|c|c|}
\hline & Male N (\%) & Female N (\%) & Total N (\%) \\
\hline Weight category & \multicolumn{3}{|c|}{ p-value } \\
\hline Underweight & $10(7.9)$ & $8(6.4)$ & $18(14.30)$ \\
\hline Normal weight & $19(15.1)$ & $17(13.5)$ & $36(28.6)$ \\
\hline Overweight & $9(7.1)$ & $5(4.0)$ & $14(11.1)$ \\
\hline Obesity & $15(11.9)$ & $43(34.1)$ & $58(46)$ \\
\hline Total & $53(42.1)$ & $73(57.9)$ & $126(100)$ \\
\hline Blood Pressure grouping & & $50(40.0)$ & \\
\hline Hypertensive & $24(19.0)$ & $26(20.5)$ & $74(59.0)$ \\
\hline Normotensive & $26(20.5)$ & $76(60.5)$ & $52(41.0)$ \\
\hline
\end{tabular}

(Hypertension was defined as systolic blood pressure of $\geq 140 \mathrm{mmHg}$ and diastolic blood pressure of $\geq 90 \mathrm{mmHg}$ )

Table 5: Blood pressure and BMI distribution by sex among adult patients with type 2 diabetes mellitus $(N=126)$.

percent of the respondents were obese with females being $34.1 \%$ and males $11.9 \%$. The difference between females and males obesity was significant $(p \leq 0.02)$.

\section{Discussion}

This study revealed that the percentage of adult patients with type 2 diabetes mellitus attending the general out-patient clinic (GOPC) using the questionnaire was $4 \%$. This shows an increase in the prevalence over $1.4 \%$ and $2.7 \%$ reported by previous studies $[9,10]$. Before now, type 2 diabetes mellitus was thought to be a disease of the Caucasians, but now due to changes in life style, diets and shifting more to sedentary life style and awareness has caused type 2 diabetes mellitus to be on the increase among the blacks and the developing countries.

The percentage of females attending the general out-patient clinic (GOPC) was $57.1 \%$ which is greater than the percentage of males (42.9\%) attending the same clinic. This is in agreement with the previous study that there was a statistical difference in the sex ratio of females attending diabetes clinic [9-11]. This could be attributed to the fact that the males are the bread winners and always leave the home in search of daily bread. The other reason could be due to gender differences in health seeking behaviour. Also men are involved in strenuous physical activities that tend to burn off most of the excess carbohydrates and fats that could have increased obesity and insulin resistance which are implicated in type 2 diabetes mellitus.

A great majority (80\%) of the adult patients with type 2 diabetes mellitus were older than 40 years of age. It was also noticed that, with increasing age, there were more adult patients with type 2 diabetes mellitus as shown in Table 1. Also at the extremes of ages, more males have type 2 diabetes mellitus than the females, while in the middle age; more females have type 2 diabetes mellitus than the males. This finding agrees with the previous report from another third world country, Mauritania in 1996 [12].

A good percentage $(35.7 \%$ and $36.5 \%)$ of the patients presented with classic osmotic symptoms which include the diad of polyuria and polydypsia.

This finding emphasizes that a high degree of diagnostic suspicion still remains important in diagnosing type 2 diabetes mellitus symptomatically.

About one third of the patients were engaged in petty trading, water leaf and vegetable farming while a minute fraction (3.2\%) was complete housewives with no jobs. A previous study conducted by Akanji and Adetuyibi [12] in 1990 reported that the overall quality of care, which include good glycaemic control, healthcare satisfaction and overall social well-being correlates with the occupation and directly to income
[13]. Consequently, those patients with poor glycaemic control may likely be engaged in low occupational status with low income which correlates with poor compliance to diabetic management.

It is observed that hypertension and type 2 diabetes mellitus coexisted, and that more females have more hypertension than the males $(36.0 \%$ vs. $19.0 \%)$. This could be attributed to the increase in prevalence of obesity among the females. In this study, hypertension was found in $55.0 \%$ of the patients. This is different from the previous reports in Ibadan and Malawi where Okesina found $42 \%$ in Ibadan and Kunwenda $45 \%$ in Malawi $[14,15]$. This increase in prevalence could be attributed to increase in obesity, defined as Body Mass Index; (BMI), $>30 \mathrm{~kg} / \mathrm{m}^{2}$, among the studied population in the General out-patient clinic (GOPC) where women were found to be more obese than the men (34.1\% vs. $11.9 \%)$. Obesity, diabetes mellitus and hypertension were found to be under a common umbrella of syndrome X [16]. These findings further agreed with the report that hypertension is a very common condition in type 2 diabetes mellitus, affecting about $20-60 \%$ of diabetic patients based upon obesity, ethnicity and age [14].

The mean HbAic level in our study was $6.92 \pm 2.8$ which is similar to the optimal level of $<7.0 \%$ recommended by the American Diabetes Association (ADA) [17]. About two thirds of the studied patients (65\%) had good glycaemic control. The male and the female diabetic patients had HbAic levels (6.8\% and $6.6 \%$ respectively) similar to the recommended optimal level of $\leq 7.0 \%$. Glycosylated hemoglobin (HbAic) elevation correlates with high morbidity and mortality [18]. It could therefore mean that diabetes complications with increasing morbidity and mortality are likely to be equally common among the patients. Those patients with poor glycaemic control may be due to poor compliance and adherence to treatment and follow-up visit. Sometimes frequent laboratory investigation and regular purchase of drugs may be economically burdensome and indirectly translate to poor compliance and adherence to treatment. These findings are supported by a study conducted by Elrayah et al. [18] in an urban town in Sudan in 2005 on economic burden of families of adult type 2 diabetes mellitus. That study reported that the economic burden of managing type 2 diabetes mellitus accounts for about $65 \%$ of family's expenditure on health [19]. Consequently, type 2 diabetic patients with poor glycaemic control may belong to families with low monthly income.

Using HbAic to monitor the quality of care was better than using fasting plasma glucose as revealed by two thirds and a third with good control respectively. These findings support the report of the American Diabetes Association that HbAic is the best index to use in evaluating the quality of care in patients with type 2 diabetes mellitus, because it is free from day to day glucose fluctuation, exercise and recent food consumption [20]. The United Kingdom prospective diabetic study 
Citation: Udonwa NE, Okoi NO (2013) The Impact of Provider Continuity Care on Quality of Care of Patients With Type 2 Diabetes Mellitus in the Family Medicine Clinic Of UCTH, Calabar, Nigeria. Contact Can Change a World. J Gen Pract 1: 109. doi: 10.4172/2329-9126.1000109

Page 5 of 6

reported that the risk of type 2 diabetes mellitus complication is strongly correlated with HbAic percentage level and poorly correlated with plasma glucose level. Consequently, a reduction in HbAic percentage level is likely to reduce the risk of type 2 diabetes mellitus complication with the lowest risk seen in those with HbAic level of less than $7 \%$ [21].

On the whole this study found that patients with provider continuity care had good glycaemic control. There was no obvious adverse effect associated with the provider continuity care during the four months study period. This contradicts the result of one study conducted in Washington DC in 1996 by the National Committee for Quality Assurance in the Health plan Employment Data and Information which found that, patients who had continuity care had no association with good glycaemic control [22]. Also our study contradicts the result of that conducted by the 19 family medicine practices in London, which reported that continuity care had no relationship with glycaemic control, but had a relationship with greater patient's satisfaction during the 10 months study period. The contradiction could be due to the large number of practices used in different locations and the longer duration of the study period of 10 months [23]. Also, lack of diabetic education which increases compliance and improved diabetes self monitoring may have contributed to the report that continuity care had no relationship with glycaemic control which was encouraged in our study.

The result of our study also agrees with the result of the study conducted by Manous et al. [23] in America in 2004 during the Third National Health and Nutrition Examination Survey (NHANES III) [23]. That study concluded that there was a relationship between continuity care and glycaemic control among patients with type 2 diabetes mellitus [24] and that when all providers and visits were accounted for, provider continuity care improves glycaemic control. One reason for these findings may be that repeated visits to the same health care provider increase the patient's opportunities for appropriate diabetic education, diabetes self care and regular diabetes mellitus monitoring tests. This finding is important because diabetes education is an essential factor in the management of patients with type 2 diabetes mellitus. Diabetes education enhances patient's compliance, adherence to diabetic treatment, prompt diabetes mellitus testing and follow-up visits.

Finally we observed that glycaemic control was the only control measure found to be related with continuity of care among the studied patients. This observation may reflect the fact that the health care providers lay more emphasis on blood glucose control and pay less attention on blood pressure and weight control. Secondly, the health care providers may view the control of blood pressure and weight as important but give it a secondary priority.

\section{Conclusion}

This study supports the opinion that provider continuity of care improves the quality of care for adult patients with type 2 diabetes mellitus.. Our findings provide reliable evidence of the importance of continuity care measures which can be used for research, monitoring and evaluation of patient-centered care. Since provider continuity care improves the glycaemic control and quality of diabetes mellitus care, it could well be considered as the best approach to management of type 2 diabetes mellitus and other chronic disease; it may also act as a guide to health care policy which decision makers could adopt in the healthcare planning.

\section{Recommendations}

The authors recommend as follows: Glycosylated hemoglobin percentage level should be done annually to assess the glycaemic control in this study center among patients with type 2 diabetes mellitus, since elevation of HbAic correlates with blood glucose concentration and type 2 diabetes mellitus complication.

That diabetes education should be given to all patients with type 2 diabetes mellitus since it increases their level of compliance and improved on their knowledge and skills on diabetes self care.

That all hypertensive patients who are taking anti-hypertensive drugs should be screened for type 2 diabetes mellitus on regular basis.

\section{Limitations}

The major limitation of this study is its location in a single health care facility which may not be a true representation of patients with type 2 diabetes mellitus in the state and Nigeria in general.

Also the adverse outcome such as prescribing errors, late presentation with advance diabetes complications that could affect the quality of care have not been ruled out.

Our study was not a double-blinded study which may have influenced the results of the glycaemic control that was done through the use of diabetes mellitus screening questionnaire.

This study was not designed to explore all the characteristics of high quality care measures which include accessibility, comprehensive clinical management, quality of life, whole patient-centered care, sustained physician patient-relationship as defined by the institute of Medicine. Rather it focused on the easily measureable quality outcomes of glycaemic control such as glycosylated hemoglobin, fasting plasma glucose, blood pressure and weight control. Consequently, more studies and more quality outcome measures are suggested.

Finally due to the small sample size of this study generalizability of the findings should be done with caution.

\section{References}

1. Sault JW (2000) Continuity of care. In: A Text book of Family Medicine. (1stedn), New York, NY: McCraw-Hill: 52-77.

2. Gill JM, Mainous AG 3rd (1998) The role of provider continuity in preventing hospitalizations. Arch Fam Med 7: 352-357.

3. Becker MH, Dranchman RH, Kirscht JP (1974) A field experiment to evaluate various outcomes of continuity of physician care. AM J Public Health 64: 10621070.

4. Khunti K, Ganguli S, Baker R, Lowy A (2001) Features of primary care associated with variations in the process and outcome of care of people with type 2 diabetes mellitus. Br J Gen Pract 51: 356-360.

5. Starfield B (1991) Primary care and health. A cross-national comparison. JAMA 266: 2268-2271

6. Polonsky KS, Sturis J, Bell GI (1996) Seminars in Medicine of the Beth Israe Hospital, Boston. Non-insulin-dependent diabetes mellitus - a genetically programmed failure of the beta cell to compensate for insulin resistance. $\mathrm{N}$ Engl J Med 334: 777-783

7. Freeman GK, Olesen F, Hjordahl P (2003) Continuity of care: an essential element of modern general practice? Fam Pract 20: 623-627.

8. Kern DH, Manious AG $3^{\text {rd }}$ (2001) Disease management for diabetes among family physicians and general internists. Opportunities or planned care? Fam Med 33: 621-625.

9. King H, Aubert RE, Herman WH (1998) Global burden of diabetes, 1995-2025 prevalence, numerical estimates, and projections. Diabetes Care 21: 14141431. 
Citation: Udonwa NE, Okoi NO (2013) The Impact of Provider Continuity Care on Quality of Care of Patients With Type 2 Diabetes Mellitus in the Family Medicine Clinic Of UCTH, Calabar, Nigeria. Contact Can Change a World. J Gen Pract 1: 109. doi: 10.4172/2329-9126.1000109

Page 6 of 6

10. Sanmartin C (2008) Diabetes prevalence and care practices. Health reports 19: $1-5$.

11. Ducorps M, Baleynaud S, Mayaudon H, Lastagne C, Baudiean BA (1996) Prevalence Survey of Diabetes in Mauritania. Diabetes Care 19: 761-763.

12. Akanji AO, Adetuyibi A (1990) The pattern of presentation of foot lesions in Nigerian Diabetic Patients. W Afr Med 9: 1-5

13. Okesina AB, Omotoso ABO, Gadzama AA, Ogunola EO (1995) Frequency of hypertension in diabetes patients: Relationship with metabolic control, Body Mass Index, Age, and Sex. Int Diabetes Care 7: 39-90.

14. Kumwenda J, Harrison AD, Nyiranda C, Minms J (1992) Diabetes mellitus and hypertension in Malawi Adult. An Med J 8: 129-131.

15. Shahady EJ (2005) Type 2 diabetes; the Metabolic Syndrome, Inflammation and Arteriosclerosis: steps to sleet a Rising Epidemic. Consultant live 45: 1-3.

16. American Diabetes Association (2001) Standards of medical care for patients with diabetes mellitus. Diabetes care 24: 533-543.

17. Skevington SM, Lotfy M, O'Connell KA, WHOQOL Group (2004) The World Health Organization's WHOQOL-BREF quality of life assessment: psychometric properties and results of the international field trial. A report from the WHOQOL group. Qual Life Res 13: 299-310.
18. Elraya $\mathrm{H}$, Elton M, Bedri A (2005) Economic Burden of families of adult type 2 diabetes mellitus in urban Sudan. Diabetes Res Chin Pract 70: 159-165.

19. Gulliford MC, Naithani S, Morgan M (2006) Measuring continuity of care in diabetes mellitus: an experience-based measure. Ann Fam Med 4: 548-555.

20. (1998) Intensive blood-glucose control with sulphonylureas or insulin compared with conventional treatment and risk of complications in patients with type 2 diabetes (UKPDS 33). UK Prospective Diabetes Study (UKPDS) Group. Lancet 352: 837-853.

21. Hpedis (1996) Health plan employer data and information set. Washington DC, National Committee for quality Assurance.

22. Greenfield Kaplan SH, Kahn R, Nino Miya J, Griftt JL (2002) Profiling care provided by different groups of physicians: effects of patient case-mix (bias) and physician-level clustering on quality assessment results. Ann Intern Med 136: 111-121.

23. Manous AG III, Koopman RI, Gill JM, Baker R, Pearson WS (2004) Relationship between continuity of care and diabetes control: Evidence from the Third National Health and Nutrition Examination Survey. Am J Public Health 94: 66-70.

24. Erasmus RI, Ebonyi E, Fakoye T (1988) Prevalence of diabetes mellitus in a Rural Nigeria population. Nigeria Med Pract 15: 22-26. 